\title{
Urinary oxalate excretion in urolithiasis and nephrocalcinosis
}

Thomas J Neuhaus, Tanja Belzer, Nenad Blau, Bernd Hoppe, Harmeet Sidhu, Ernst Leumann

\begin{abstract}
Aims-To investigate urinary oxalate excretion in children with urolithiasis and/or nephrocalcinosis and to classify hyperoxaluria (HyOx).

Methods-A total of 106 patients were screened. In those in whom the oxalate: creatinine ratio was increased, 24 hour urinary oxalate excretion was measured. Liver biopsy and/or genomic analysis was performed if primary hyperoxaluria $(\mathbf{P H})$ was suspected. Stool specimens were examined for Oxalobacter formigenes in HyOx not related to $\mathrm{PH}$ type 1 or 2 (PH1, PH2) and in controls.

Results-A total of 21 patients screened had HyOx (>0.5 mmol/24 h per $1.73 \mathrm{~m}^{2}$ ); they were classified into five groups. Eleven had PH (PH1 in nine and neither PH1 nor PH2 in two). Six had secondary HyOx: two enteric and four dietary. Four could not be classified. Seven patients had concomitant hypercalciuria. Only one of 12 patients was colonised with $O$ formigenes compared to six of 13 controls.

Conclusions-HyOx is an important risk factor for urolithiasis and nephrocalcinosis in children, and can coexist with hypercalciuria. A novel type of $\mathrm{PH}$ is proposed. Absence of $O$ formigenes may contribute to $\mathrm{HyOx}$ not related to PH1. (Arch Dis Child 2000;82:322-326)
\end{abstract}

Keywords: hyperoxaluria; nephrocalcinosis; urolithiasis; Oxalobacter formigenes

Nephrology Unit, University Children's Hospital,

Steinwiesstrasse 75 , CH-8032 Zurich, Switzerland

T J Neuhaus

T Belzer

B Hoppe

E Leumann

Division of Clinical

Chemistry and

Biochemistry,

University Children's

Hospital

N Blau

Division of Oxalate

Research, Ixion

Biotechnology,

Alachua, Florida, USA

H Sidhu

Correspondence to:

Dr Neuhaus

email: Thomas.Neuhaus@

kispi.unizh.ch

Accepted 7 January 2000 urolithiasis or nephrocalcinosis are detected incidentally on ultrasound or abdominal $x$ ray.

The majority of renal calculi in children are (as in adults) composed of calcium oxalate. ${ }^{1-4}$ Calcium oxalate stones are commonly attributed to (idiopathic) hypercalciuria although the aetiology often remains undetermined. Only a few children suffer from inherited disorders, for example, primary hyperoxaluria type 1 or type $2(\mathrm{PH} 1, \mathrm{PH} 2),{ }^{5}$ renal tubular acidosis, or Dent's disease. Metabolic screening of paediatric renal stone formers is essential, but is often confined to urinary calcium, cystin, and uric acid excretion, although hyperoxaluria ( $\mathrm{HyOx}$ ) and hypocitraturia contribute to the formation of calcium

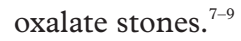

Persistent $\mathrm{HyOx}$ in children is often related to PH1 or PH2. ${ }^{5}{ }^{6}$ Enteric HyOx is the consequence of malabsorption and steatorrhoea, for example, in patients with short bowel syndrome, inflammatory bowel disease, and cystic fibrosis. ${ }^{10-12}$ Excessive intake of nutrients high in oxalate content (for example, beetroot, dark chocolate, ice tea, rhubarb, spinach) may result in transient dietary $\mathrm{HyOx} .{ }^{13}$ Recently, the absence of intestinal Oxalobacter formigenes, an oxalate degrading bacterium, has been reported as a potential risk factor for $\mathrm{HyOx}$ in children with cystic fibrosis. ${ }^{12}$

The objectives of this study were: (1) the investigation of the urinary oxalate excretion in children with urolithiasis and/or nephrocalcinosis; and (2) classification and follow up of the patients with $\mathrm{HyOx}$.

\section{Patients and methods}

PATIENTS

All 106 patients with a diagnosis of urolithiasis and/or nephrocalcinosis seen between 1990 and 1997 were enrolled in the study: 75 children (49 boys) had urolithiasis, 20 (seven boys) had nephrocalcinosis, and 11 (eight boys) had both urolithiasis and nephrocalcinosis. Age at presentation ranged from 2 weeks to 14 years. In addition, all siblings of patients with $\mathrm{PH}$ were investigated. Patients with known secondary forms of nephrocalcinosis (ex-prematures who had received furosemide, patients with hypophosphataemic rickets or vitamin $\mathrm{D}$ intoxication) were excluded. Our hospital is both a primary care centre for the greater area of Zurich and a tertiary referral centre for the eastern part of Switzerland. Children with urolithiasis and nephrocalcinosis are referred if they have metabolic disturbances (for example, hypercalciuria), require extracorporeal shock wave lithotripsy, or have renal insufficiency.
METHODS

Screening was performed by determination of the oxalate:creatinine ratio in an acidified spot morning urine. If the ratio was increased compared with sex and age related normal values, ${ }^{14}{ }^{15}$ at least one 24 hour urinary collection was performed to measure oxalate, glycolate, glycerate, and calcium excretion. The urine was directly voided into sampling bottles, containing $10 \mathrm{ml} 6 \mathrm{M} \mathrm{HCl}$ per litre of urine. An aliquot was stored at $-20^{\circ} \mathrm{C}$ and 
analysed within one month. The adequacy of urine collection was checked by comparing the measured creatinine excretions with normal values. ${ }^{16} \mathrm{~A}$ dietary history was taken with emphasis on calcium and oxalate intake. The extent of nephrocalcinosis was graded according to the sonographic findings (grades $1-3) .{ }^{17}$

Urinary concentrations of citrate, magnesium, phosphate, potassium, sodium, sulphate, and uric acid, and urinary $\mathrm{pH}$ were also measured. Urinary calcium oxalate saturation was calculated from these parameters using a PC based computer program (EQUIL 2). ${ }^{18}$ Results were compared with sex and age related values. ${ }^{19}$ Separation and quantification of oxalate, citrate, glycerate, glycolate, and sulphate was performed using a Dionex Series 4000i gradient ion chromatography system (Dionex, Sunnyvale, California).$^{20}$ Low background conductivity was ensured by addition of $25 \mathrm{mM}$ sulphuric acid. Other solutes were measured with a Synchron CX-6 analyser (Beckmann, Brea, California): calcium (colorimetric cresolphthalein complex method), creatinine (standard kinetic Jaffé procedure), magnesium (xylidyl blue reaction), phosphate (ultraviolet molybdat method), potassium and sodium (ion selective electrodes). As urinary collections were acidified, uric acid (uricase method) and urinary $\mathrm{pH}$ were measured in a fresh morning urine following the collection. Renal stones were analysed by $x$ ray diffraction. Normal 24 hour urinary excretion values for oxalate, glycolate, citrate, and calcium were defined as: oxalate $<0.5 \mathrm{mmol}$, glycolate $<0.5$ mmol, and citrate $>0.8 \mathrm{mmol}$ per $1.73 \mathrm{~m}^{2}$ body surface area; calcium $\leqslant 0.1 \mathrm{mmol}$ per $\mathrm{kg}$ body weight. ${ }^{19}$

Liver biopsy and/or molecular analysis were performed in patients with suspected PH (G Rumsby, University College London Hospitals, London, $\mathrm{UK}^{21}$ ). The catalytic activity and the level of immunoreactive alanine:glyoxylate aminotransferase (AGT) protein (PH1), and the catalytic activity of glyoxylate reductase/ hydroxypyruvate reductase (PH2) were measured in liver tissue. ${ }^{22}$ The AGXT (PH1) gene was screened for the various normally occurring polymorphisms and all hitherto known PH1 specific mutations. ${ }^{22}$

Fresh stool specimens were examined for Oxalobacter formigenes. Faecal swabs (approximately $25 \mathrm{mg}$ of stool sample/swab) were obtained from all 12 patients with $\mathrm{HyOx}$ not related to $\mathrm{PH} 1$, and from 13 age and sex matched healthy children, using the Cary-Blair culture swab transport system (Difco Laboratories, Detroit, Michigan), and sent to Ixion Biotechnology Inc. (Alachua, Florida) for detection of $O$ formigenes by culture and DNA analysis. ${ }^{23}$ All children had been off antibiotics for at least one month.

Informed consent was obtained from all parents. The study was approved by the local ethical committee.

\section{Results}

$\mathrm{HyOx}$ was detected in 21 (11 boys) of the 106 investigated children $(20 \%)$ - that is, in nine of 75 patients with urolithiasis, three of 20 with nephrocalcinosis, and nine of 11 with both urolithiasis and nephrocalcinosis. None of the 21 patients had a primary anatomical malformation. Patients with $\mathrm{HyOx}$ were classified into five groups: $\mathrm{PH} 1$; $\mathrm{PH}$ which was neither $\mathrm{PH} 1$ nor $\mathrm{PH} 2$; enteric $\mathrm{HyOx}$; dietary $\mathrm{HyOx}$; and non-classified $\mathrm{HyOx}$.

PRIMARY HYPEROXALURIA

Primary hyperoxaluria type 1

PH1 was diagnosed in nine patients (reported in part previously ${ }^{24} 25$ ). Urinary calcium oxalate saturation was persistently increased in all patients, whereas urinary citrate was always normal. One patient was different: he had only moderate $\mathrm{HyOx}(0.5-1.0 \mathrm{mmol} / 24 \mathrm{~h}$ per $1.73 \mathrm{~m}^{2}$ in 10 of 17 urinary collections); he was the only PH1 patient with hypercalciuria (in 16 of 17 analyses); and his stones consisted of a mixture of calcium oxalate monohydrate $(90 \%)$ and dihydrate $(10 \%)$ in contrast to pure calcium oxalate monohydrate in the other $\mathrm{PH} 1$ patients.

Primary hyperoxaluria, neither PH1 nor PH2 Two patients of Swiss and Tamil origin with early onset of bilateral stone formation at the age of 1.3 and 2.3 years, respectively, also had persistent HyOx (table 1; patients 1 and 2). Urinary calcium oxalate saturation was intermittently (range 4.7-11.0, normal $<8$, patient 1) or persistently (range 6.7-25.0, normal $<6$, patient 2) increased whereas urinary glycolate, glycerate, calcium, and citrate excretion were normal. Stones of both patients were composed of calcium oxalate $(70 \%$ monohydrate, $30 \%$ dihydrate). There was no evidence of malabsorption, and dietary oxalate intake was normal. PH1 and PH2 were definitely excluded by liver biopsy which showed normal catalytic activity and immunoreactivity of alanine:glyoxylate aminotransferase and glyoxylate reductase/hydroxypyruvate reductase. Treatment included high fluid intake, dietary oxalate restriction, and administration of potassium citrate and pyridoxine. Although therapy had no effect on urinary oxalate excretion, both patients have not formed further stones so far. Both have a slightly increased plasma creatinine concentration.

\section{SECONDARY HYPEROXALURIA}

Enteric hyperoxaluria

Two patients with recurrent calcium oxalate stones ( $60 \%$ monohydrate, $40 \%$ dihydrate) suffered from enteric $\mathrm{HyOx}$ after extensive jejunoileal resection (table 1 ; patients 3 and 4). $\mathrm{HyOx}$ was inconsistent and ranged from $<0.5$ to $>1.0 \mathrm{mmol} / 24 \mathrm{~h}$ per $1.73 \mathrm{~m}^{2}$. Urinary calcium excretion fluctuated from normal to high. Urinary citrate (off treatment) was persistently low in both patients $(0.25-0.7$ $\mathrm{mmol} / 24 \mathrm{~h}$ per $1.73 \mathrm{~m}^{2}$, patient 3; 0.07-0.5, patient 4). High fluid intake, dietary oxalate restriction, and potassium citrate were given. High fluid intake was difficult to achieve in one patient (patient 3) as it caused diarrhoea; her plasma creatinine was slightly increased. The normocalciuric patient (patient 4) received oral calcium supplementation. 
Table 1 Clinical and laboratory findings of 12 patients with hyperoxaluria (not related to PH1 or PH2)

\begin{tabular}{|c|c|c|c|c|c|c|c|c|c|c|}
\hline \multirow[b]{2}{*}{$\begin{array}{l}\text { Patient } \\
\text { no. }\end{array}$} & \multirow[b]{2}{*}{$\begin{array}{l}\text { Urolith- } \\
\text { iasis* }\end{array}$} & \multirow[b]{2}{*}{$\begin{array}{l}\text { Nephro- } \\
\text { calcinosist }\end{array}$} & \multirow[b]{2}{*}{$\begin{array}{l}24 \text { h urinary } \\
\text { collections }(n)\end{array}$} & \multicolumn{3}{|c|}{$\begin{array}{l}\text { Urinary oxalate excretion } \\
\left(m m o l / 24 \mathrm{~h} \text { per } 1.73 \mathrm{~m}^{2}\right)\end{array}$} & \multirow{2}{*}{$\begin{array}{l}\text { Elevated } \\
\text { calcium oxalate } \\
\text { saturation } \neq(n)\end{array}$} & \multirow{2}{*}{$\begin{array}{l}\text { Hypercalciuria } \\
(>0.1 \mathrm{mmol} / 24 \mathrm{~h} \\
\text { per } \mathrm{kg}) \text { (n) }\end{array}$} & \multirow[b]{2}{*}{$\begin{array}{l}\text { Current } \\
\text { age }(y)\end{array}$} & \multirow{2}{*}{$\begin{array}{l}\text { Plasma } \\
\text { creatinine } \\
(\mu \mathrm{mol} / \mathrm{l})\end{array}$} \\
\hline & & & & $<0.5$ & $\geqslant 0.5$ & $\geqslant 1.0$ & & & & \\
\hline \multicolumn{11}{|c|}{ Primary hyperoxaluria, neither } \\
\hline 1 & S & Absent & 7 & 0 & 1 & 6 & 4 & 0 & 4.8 & 64 \\
\hline 2 & $S$ & Absent & 8 & 0 & 4 & 4 & 8 & 1 & 4.4 & 61 \\
\hline \multicolumn{11}{|c|}{$\begin{array}{l}\text { Secondary hyperoxaluria: } \\
\text { enteric hyperoxaluria }\end{array}$} \\
\hline 3 & $\mathrm{R}$ & Absent & 7 & 4 & 3 & 0 & 3 & 5 & 11.9 & 81 \\
\hline 4 & $\mathrm{R}$ & Absent & 11 & 0 & 3 & 8 & 9 & 0 & 15.0 & 78 \\
\hline \multicolumn{11}{|c|}{$\begin{array}{l}\text { Secondary hyperoxaluria: } \\
\text { dietary hyperoxaluria }\end{array}$} \\
\hline 5 & $\mathrm{R}$ & Absent & 5 & 3 & 1 & 1 & 2 & 1 & 16.8 & 79 \\
\hline 6 & $\mathrm{R}$ & 2 & 10 & 5 & 3 & 2 & 5 & 9 & 15.5 & 57 \\
\hline 7 & $\mathrm{R}$ & Absent & 8 & 5 & 3 & 0 & 4 & 2 & 20.8 & 70 \\
\hline 8 & S & Absent & 1 & 0 & 1 & 0 & 1 & 0 & 11.7 & 60 \\
\hline \multicolumn{11}{|c|}{$\begin{array}{l}\text { Non-classified } \\
\text { hyperoxaluria }\end{array}$} \\
\hline 9 & $\mathrm{R}$ & 3 & 12 & 3 & 8 & 1 & 12 & 12 & 14.0 & 87 \\
\hline 10 & S & Absent & 11 & 6 & 5 & 0 & 7 & 9 & 10.3 & 70 \\
\hline 11 & - & 2 & 12 & 5 & 6 & 1 & 11 & 9 & 11.8 & 63 \\
\hline 12 & $S$ & Absent & 3 & 1 & 2 & 0 & 2 & 3 & 13.5 & 70 \\
\hline
\end{tabular}

${ }^{\star} \mathrm{S}$, single; R, recurrent episode(s) of urolithiasis. $\dagger$ See Patriquin and Robitaille. ${ }^{17} \ddagger$ See Hoppe et al. ${ }^{19}$

\section{Dietary hyperoxaluria}

Dietary diaries and notable fluctuation of $\mathrm{HyOx}$ suggested dietary $\mathrm{HyOx}$ in four children. Three had an excessive oxalate intake (table 1; patients 5-7) and one (patient 8) -as advised elsewhere-had vigorous calcium restriction. Family history was positive for urolithiasis in two patients (patients 6 and 7). Urinary citrate excretion was always normal. All examined stones were composed of a mixture of calcium oxalate monohydrate and dihydrate. After adjusting the dietary habits, urinary oxalate excretion returned to normal, haematuria disappeared, and the further clinical course was uneventful in all four patients.

NON-CLASSIFIED HYPEROXALURIA

No plausible explanation was found for the intermittent $\mathrm{HyOx}$ in four patients (table 1; patients 9-12). All had concomitant hypercalciuria (which had been the primary reason for referral), contributing to the increased urinary calcium oxalate saturation. Family history was positive for urolithiasis in one patient (patient 9). Urinary citrate excretion was always normal. All examined stones were composed of a mixture of calcium oxalate monohydrate and dihydrate. Dietary oxalate and calcium intake was normal. High fluid intake and dietary oxalate restriction were recommended, and potassium citrate and/or thiazide diuretics were intermittently administered, without affecting HyOx. One patient (patient 9) with recurrent urolithiasis underwent liver biopsy which ruled out both $\mathrm{PH} 1$ and $\mathrm{PH} 2$; analysis of the chloride channel gene CLCN5 (Dent's disease) was also normal (RV Thakker, Hammersmith Hospital, London, UK). Plasma creatinine was slightly increased in two patients (patients 9 and 10).

Oxalobacter formigenes

Stool specimens were examined for $O$ formigenes in all 12 patients with $\mathrm{HyOx}$ not related to PH1. Only one (patient 9; 8\%) was colonised compared to six of $13(46 \%)$ controls. All controls had urinary oxalate:creatinine ratio in the normal range; the ratio was slightly, but not significantly lower in the colonised group compared to the non-colonised group (32 versus 46 $\mathrm{mmol} / \mathrm{mol}$ ).

None of the 21 patients had hyperuricosuria. ${ }^{4}$ Urinary sodium excretion was not significantly different between the seven hypercalciuric patients compared to the 14 normocalciuric patients (71 versus 83 $\mathrm{mmol} / 24 \mathrm{~h}$ per $\mathrm{m}^{2}$ ).

\section{Discussion}

The majority of renal stones in children are composed of calcium oxalate. ${ }^{1-48}$ Several factors contribute to the formation of calcium oxalate crystals: $\mathrm{HyOx}$, hypercalciuria, hypocitraturia, low urinary volume, anatomical malformations with urinary stasis, and dietary habits. ${ }^{1-4}$ 7-11 13 Our data confirm the importance of $\mathrm{HyOx}$ as a risk factor for urolithiasis and/or nephrocalcinosis in children. HyOx was present in a substantial percentage of patients with either urolithiasis or nephrocalcinosis. Moreover, $\mathrm{HyOx}$ was found in almost all children presenting with both urolithiasis and nephrocalcinosis.

Routine urinary oxalate determination is not common practice as collection and measurement of urinary oxalate are laborious and delicate. Indeed, a recent nationwide US survey on diagnostic procedures showed that even in patients with suspected $\mathrm{PH}$ urinary oxalate was only measured in $61.5 \%$ of these patients. ${ }^{26}$ Urinary oxalate excretion has only rarely been investigated in paediatric stone formers. Two studies, one from Germany ${ }^{27}$ and one from India, ${ }^{28}$ have shown a similar prevalence of $\mathrm{HyOx}-15 \%$ (six of 40 patients) and 9\% (three of 32), respectively.

Classification of $\mathrm{HyOx}$ may be difficult. $\mathrm{HyOx}$ was associated with primary hyperoxaluria in less than half of our patients. Children with $\mathrm{PH} 1$ or $\mathrm{PH} 2$ usually have notable and 
persistent elevation of urinary oxalate excretion $\left(\geqslant 1 \mathrm{mmol} / 24 \mathrm{~h}\right.$ per $1.73 \mathrm{~m}^{2}$ ) and normal or low urinary calcium excretion. Some rare patients also have hypercalciuria. Liver biopsy and/or molecular analysis confirm the clinical diagnosis, but do not predict the outcome. ${ }^{22}{ }^{24}$ The clinical course of PH1 is variable between patients and within families. ${ }^{56242529}$ Family screening has shown completely asymptomatic siblings with $\mathrm{PH} 1 .^{24}$

Two patients with persistent $\mathrm{HyOx}$ had clinical and urinary findings compatible with primary hyperoxaluria, but both $\mathrm{PH} 1$ and $\mathrm{PH} 2$ were excluded by liver biopsy. In contrast to patients with $\mathrm{PH} 1,{ }^{30}$ the stones contained not only calcium oxalate monohydrate, but also calcium oxalate dihydrate. Oxalate restriction and long term administration of pyridoxine had no effect on $\mathrm{HyOx}$. These findings suggest a novel type of primary hyperoxaluria, different from $\mathrm{PH} 1$ and $\mathrm{PH} 2$, tentatively called "atypical PH". Further evidence for a novel type was recently presented at the 5th Workshop on Primary Hyperoxaluria. ${ }^{30}$

Secondary hyperoxaluria is either enteric or dietary, apart from intoxication. Enteric $\mathrm{HyOx}$ resulting from malabsorption and steatorrhoea has only occasionally been reported in children. ${ }^{10-12}{ }^{27}$ In patients with enteric $\mathrm{HyOx}$, calcium binds to fatty acids instead of oxalate, and this soluble oxalate is better absorbed. Hypocitraturia - in this series confined to enteric $\mathrm{HyOx}$ - is an additional lithogenic risk factor in these patients, and is caused at least in part by intestinal alkali loss. ${ }^{31}$ Dietary $\mathrm{HyOx}$ results from excessive intake of nutrients high in oxalate content (or vigorous calcium restriction), and is usually associated with intermittent and variable $\mathrm{HyOx}$ depending on oxalate intake. ${ }^{13}{ }^{32}$ However, only $5-10 \%$ of the urinary oxalate normally originates from daily nutrition, and this fraction is even lower in patients with $\mathrm{PH} 1$, considering their high endogeneous oxalate production. ${ }^{52}{ }^{25}$ Repeated 24 hour urinary collections and a dietary history are mandatory.

A few patients with intermittent $\mathrm{HyOx}$ and concomitant hypercalciuria could not be classified as there was no evidence of primary or secondary $\mathrm{HyOx}$ based on clinical and urinary findings. The combination of hypercalciuria and $\mathrm{HyOx}$ exerted a synergistic effect on the elevation of urinary calcium oxalate saturation with subsequent formation of urolithiasis and nephrocalcinosis.

The calculation of the urinary calcium oxalate saturation (EQUIL 2), incorporating various lithogenic and inhibitory substances, is a tool to assess the risk of stone formation. ${ }^{18}$ Although its predictive value is controversial in adult stone formers ${ }^{33}$ and could not strictly be proven in this study, the data on urinary calcium oxalate saturation were helpful for the clinical guidance of $\mathrm{HyOx}$ children. If urinary calcium oxalate saturation was increased, suggesting at least partial non-compliance, patients were promptly advised to adhere more strictly to treatment consisting of high fluid intake, citrate administration and-except in $\mathrm{PH} 1$ - dietary oxalate restriction. ${ }^{25}$
If end stage renal failure occurs in $\mathrm{PH}$, combined liver-kidney transplantation is required. ${ }^{34}$ In the past, many adult idiopathic calcium oxalate stone formers were advised to adopt a low calcium diet. However, this may lead to increased intestinal oxalate absorption and subsequent $\mathrm{HyOx}$, as less calcium is available to bind oxalate and to form poorly absorbable calcium oxalate complexes in the gut. ${ }^{75}$ Indeed, even a minor increase of the urinary concentration of oxalate (but not of calcium) exerts a substantial lithogenic effect. ${ }^{736}$ Keeping in line with this concept is a recent study showing that high calcium intake prevents further stone formation. ${ }^{37}$

The absence of $O$ formigenes from the intestinal tract has recently been reported as a potential risk factor for $\mathrm{HyOx}$ in children with cystic fibrosis. ${ }^{12} \mathrm{O}$ formigenes scavenges and degrades dietary oxalate in the human gut and creates a transepithelial gradient favourable for secretion of oxalate. In PH1, intestinal absorption of exogenous oxalate is of little relevance compared to gross endogenous overproduction. On the other hand, absence of $O$ formigenes and subsequent increased intestinal oxalate absorption may contribute to the excessive urinary oxalate excretion in the other forms of $\mathrm{HyOx}$, as only one of these patients was colonised compared to up to $70 \%$ in healthy populations. ${ }^{23}$ However, more data on larger patient groups are needed.

\section{CONCLUSIONS}

(1) Hyperoxaluria is an important risk factor in children with urolithiasis and/or nephrocalcinosis, and can coexist with hypercalciuria. Thus, initial routine diagnostic work up requires measurement of urinary oxalate. (2) Classification of $\mathrm{HyOx}$ is difficult. (3) At least one novel type of $\mathrm{PH}$ besides $\mathrm{PH} 1$ and $\mathrm{PH} 2$ is proposed. (4) Absence of $O$ formigenes may contribute to $\mathrm{HyOx}$.

We thank Mrs Ana Matasovic for her technical work and Dr G Rumsby for performing the enzymic and molecular analysis. Proesmans W, ed. Therapeutic strategies in children with renal disease. Baillieres Clinical Paediatrics 1997:653-74.

2 Laufer J, Boichis H. Urolithiasis in children: current medical management. Pediatr Nephrol 1989;3:317-31.

3 Polinsky MS, Kaiser BA, Baluarte HJ. Urolithiasis in childhood. Pediatr Clin North Am 1987;34:683-709.

4 Stapleton B. Clinical approach to children with urolithasis. Semin Nephrol 1996;16:389-97.

5 Latta K, Brodehl J. Primary hyperoxaluria type I. Eur F Pediatr 1990;149:518-22.

6 Kemper MJ, Conrad S, Müller-Wiefel DE. Primary hyperoxaluria type 2. Eur f Pediatr 1997;156:509-12.

7 Hess B, Hasler-Strub U, Ackermann D, Jaeger P. Metabolic evaluation of patients with recurrent idiopathic calcium evaluation of patients with recurrent idiopathic calcium
nephrolithiasis. Nephrol Dial Transplant 1997;12:1362-8.

nephrolithiasis. Nephrol Dial Transplant 1997;12:1362-8.
8 Drach GW. Metabolic evaluation of paediatric patients with stones. Urol Clin North Am 1995;22:95-100.

9 Akçay T, Konukoglu D, Celik C. Hypocitraturia in patients with urolithiasis. Arch Dis Child 1996;74:350-1.

10 Carter BS, Withworth HS. Nephrolithiasis in an infant with short-bowel syndrome. Clin Pediatr 1994;33:741-2.

11 Jones DP, Stapleton FB, Whitington G, Noe HN. Urolithiasis and enteric hyperoxaluria in a child with steatorrhea. Clin Pediatr 1987;26:304-6.

12 Sidhu H, Hoppe B, Hesse A, et al. Absence of Oxalobacter formigenes in cystic fibrosis patients: a risk factor for hyperoxaluria. Lancet 1998;352:1026-9.

13 Balcke P, Zazgornik J, Sunder-Plassmann G, et al. Transient hyperoxaluria after ingestion of chocolate as a high risk factor for calcium oxalate calculi. Nephron 1989;51:32-4.

14 Leumann EP, Dietl A, Matasovic A. Urinary oxalate and glycolate excretion in healthy infants and children. Pediatr Nephrol 1990;4:493-7. 
15 Barratt TM, Kasidas GP, Murdoch I, Rose GA. Urinary oxalate and glycolate excretion and plasma oxalate concenoxalate and glycolate excretion and plas
tration. Arch Dis Child 1991;66:501-3.

16 Graystone JE. Creatinine excretion during growth. In Check DB, ed. Human growth. Philadelphia: Lea and Febiger, 1968:182-97.

17 Patriquin H, Robitaille P. Renal calcium deposition in children: sonographic demonstration of the Anderson-Carr progression. Am f Roentgenol 1986;146:1253-6.

18 Werness PG, Brown CM, Smith LH, Finlayson B. Equil 2: a basic computer program for the calculation of urinary saturation. F Urol 1985;134:1242-4.

19 Hoppe B, Jahnen A, Bach D, Hesse A. Urinary calcium oxalate saturation in healthy infants and children. $\mathcal{F}$ Urol 1997; 158:557-9.

20 Blau N, Matasovic A, Lukasiewicz-Wedlechowicz A, Heizmann CW, Leumann E. Simultaneous determination of oxalate, glycolate, citrate, and sulfate from dried urine filter paper spots in a paediatric population. Clin Chem 1998;44: paper sp

21 v Schnakenburg C, Rumsby G, Leumann E. The role of genetic diagnosis in primary hyperoxaluria type 1 in Swiss patients [abstract]. Monatsschr Kinderheilkd 1997, 145(suppl):S15.

22 Danpure CJ, Purdue RE. Primary hyperoxaluria. In: Scriver $\mathrm{CR}$ et al, eds. The metabolic and molecular bases of inherited disease. 7th edition. New York: McGraw-Hill, 1995:2385424

23 Sidhu H, Allison M, Peck AB. Identification and classification of Oxalobacter formigenes strains by using oligonucleotide probes and primers. F Clin Microbiol 1997; 35:350-3.

24 Hoppe B, Danpure CJ, Rumsby G, et al. A vertical (pseudodominant) pattern of inheritance in the autosomal recessive disease primary hyperoxaluria type 1: lack of relationship between genotype, enzymic phenotype, and disease severity. Am $¥$ Kidney Dis 1997:29:36-44.

25 Leumann E, Hoppe B, Neuhaus TJ. Management of primary hyperoxaluria: efficacy of oral citrate administraprimary hyperoxaluria: efficacy of oral
tion. Pediatr Nephrol 1993;7:207-11.
26 Hoppe B, Langman CB. Primary hyperoxaluria: from diagnosis to transplantation-a nationwide survey [abstract]. F nosis to transplantation-a natio

27 Böhles H, Brandl U, Schott G, Stehr K. Clinical and chemical parameters of kidney stone formation in paediatrics. Monatsschr Kinderheilkd 1984;132:158-62.

28 Hari P, Bagga A, Vasudev V, Singh M, Srivastava N Aetiology of nephrolithiasis in north Indian children. Pediatr Nephrol 1995;9:474-5.

29 Cochat P, Deloraine A, Rotily M, Olive F, Liponski I, Deries N. Epidemiology of primary hyperoxaluria type 1 . Nephrol Dial Transplant 1995;10(suppl 8):3-7.

30 Milliner D. Atypical primary hyperoxaluria: PH type III? 5th Workshop on Primary Hyperoxaluria, 1999, Kappel/ Zurich, Switzerland. Nephrol Dial Transplant 1999;14: 2787-8

31 Sutton RA, Walker VR. Enteric and mild hyperoxaluria Miner Electrolyte Metab 1994;20:352-60.

32 Holmes RP, Goodman HO, Assimos DG. Dietary oxalate and its intestinal absorption. Scanning Microsc 1995;9: 1109-18.

33 Robert M, Boularan AM, Delbos O, Guiter J, Descomps B Study of calcium oxalate crystalluria on renal and vesical urines in stone formers and normal subjects. Urol Int 1998; 60:41-6.

34 Jamieson NV. The European primary hyperoxaluria type 1 transplant registry report on the results of combined liver/ idney transplantation for primary hyperoxaluria 1984 1994. Nephrol Dial Transplant 1995;10(suppl 8):33-7.

35 Reusz GS, Dobos M, Byrd D, Sallay P, Miltenyi M, Tulassay T. Urinary calcium and oxalate excretion in children. Pediatr Nephrol 1995;9:39-44.

36 Robertson WG, Peacock M. The cause of idiopathic calcium stone disease: hypercalciuria or hyperoxaluria? Nephron 1980;26:105-10.

37 Curhan GC, Willett WC, Rimm EB, Stampfer MJ. A prospective study of dietary calcium and other nutrients and the risk of symptomatic kidney stones. $N$ Engl f Med 1993;328:833-8.

\section{MilliPaed 2000 Congress}

\section{7-21 May 2000, Sun City, South Africa}

This biennial conference of the South African Paediatric Association and the South African Association of Paediatric Surgeons aims to meet the medical and surgical needs of children in South Africa but will be of interest to delegates worldwide. The scientific program will provide a blend of original research, and state of the art review for which this meeting is renowned. Plenary sessions include medical information technology, advances in neonatology, epilepsy: "should we be treating fits?", management of short stature, and much more.

For further details of the congress, please contact: Mrs Yvonne Pyne-James, RSVP Events Management c.c., PO Box 1105, Cramerview 2060, South Africa (tel: +27 11463 4064, fax: +27 11463 1041, e-mail: rsvp@yebo.co.za, website: www.millipaed.co.za) 